\title{
Democracia Deliberativa: uma Análise do Decreto no 8.243
}

\author{
Deliberative Democracy: An Analysis of Executive Order No. 8243 \\ Democracia Deliberativa: Un análisis del Decreto n 8.243
}

Resumo: 0 propósito deste artigo é identificar aproximações entre elementos da teoria da democracia deliberativa e o Decreto n. 8.243 da Presidência da República do Brasil, de maio de 2014, que institui a Política Nacional de Participação Social (PNPS) e o Sistema Nacional de Participação Social (SNPS). Diversos autores consideram a democracia deliberativa adequada à contemporaneidade de valorizar e criar condições de uma participação direta do cidadão na definição de políticas públicas e de práticas de administração pública. Considerando os objetivos e as diretrizes de fortalecer e articular mecanismos e instâncias democráticas de diálogo e criar condições de atuação conjunta entre administração pública federal e sociedade civil, observaram-se nesse Decreto diversos elementos democrático-deliberativos importantes para a consolidação da democracia brasileira. Observou-se também a coerência entre 0 Decreto e as perspectivas democráticas previstas na Constituição Federal de 1988, que prevê que o cidadão pode exercer seu poder democrático diretamente ou por meio de representantes eleitos.

Palavras-chave: democracia deliberativa, participação social, política nacional de participação social.

Jorge Sundermann - jsundermann@hotmail.com

Professor da Pontifícia Universidade Católica de Minas Gerais, Belo Horizonte, MG, Brasil

José Roberto Pereira - jrobertopereira2013@gmail.com

Professor da Universidade Federal de Lavras, Lavras, MG, Brasil.

Claudemir Francisco Alves - Claudemir_alves@uol.com.br

Professor da Pontifícia Universidade Católica de Minas Gerais, Departamento de Filosofia, Belo Horizonte, MG, Brasil.

Mozar José de Brito - mozarjdb@ufla.br

Professor da Universidade Federal de Lavras, Departamento de Administração e Economia, Lavras, MG, Brasil.

Artigo submetido no dia 10-07-2015 e aprovado em 28-02-2016.

DOI: http://dx.doi.org/10.12660/cgpc.v21n68.52967 
Jorge Sundermann - José Roberto Pereira - Claudemir Francisco Alves - Mozar José de Brito

\section{Abstract}

This article seeks to identify similarities between elements of the theory of deliberative democracy and Executive Order No. 8243 of the President's Office of the Republic of Brazil, dated May 2014, which would institute a National Social Participation Policy and the National Social Participation System. Several authors consider deliberative democracy to be appropriate to contemporaneity and a way of promoting and creating conditions for direct citizen participation in defining public policy and administration practices. Considering the objectives and guidelines for strengthening and promoting mechanisms and channels for democratic dialogue and creating conditions for joint action between the federal government and civil society, many important democratic-deliberative elements for the consolidation of Brazilian democracy have been observed in the Executive Order. There is a coherence between the Executive Order and the democratic prospects provided for in the Federal Constitution of 1988, which establishes that citizens can exercise their democratic power directly or through elected representatives.

Keywords: Deliberative Democracy, Social Participation, Direct Participation, National Social Participation Policy, Public Administration.

\section{Resumen}

Este artículo intenta identificar las aproximaciones entre los elementos de la teoría de la Democracia Deliberativa y el decreto $n^{\circ} 8.243$ de la Presidencia de la República de Brasil, de mayo de 2014, en que instituiria la Política Nacional de Participación Social y el Sistema Nacional de Participación. Diversos autores consideran la democracia deliberativa adecuada para la contemporaneidad y, una forma de valorizar y crear condiciones de una participación directa del ciudadano en definición de políticas y prácticas de administración pública. Considerando los objetos y directrices de fortalecer y articular mecanismos e instancias democráticas del diálogo y crear condiciones de actuación conjunta entre administración pública federal y la sociedad civil, se observaron en el Decreto diversos elementos importantes para la consolidación de la democracia brasileña. Se observó la coherencia entre el Decreto y perspectiva democrática prevista en la Constitución Federal de 1988, que prevé que el ciudadano puede ejercer su poder democrático directamente o por medio de representantes electos.

Palabras clave: Democracia deliberativa, participación social, participación directa, Política Nacional de Participación Social, Administración pública.

\section{Introdução}

Ao tratarem da organização de sociedades contemporâneas, Marques (2009b), Bohman (2009), Cohen (2009) e Johnson (2011) consideram a democracia deliberativa adequada à contemporaneidade. A deliberação é entendida como um processo oriundo de debates, conversações cívicas e discussões políticas. Podem acontecer em ambientes formais ou informais e resultam em contribuições para a criação de espaços públicos que atendam às demandas ou aos interesses dos cidadãos (Marques, 2009b).

No entanto, a perspectiva de espaços públicos instituídos ou que buscam instituir a participação efetiva dos cidadãos na construção social, embora teoricamente adequada para a contemporaneidade, apresenta desafios significativos para sua implementação efetiva.

Em 23 de maio de 2014, a Presidência da República do Brasil, publicou o Decreto $\mathrm{n}$. 8.243, instituindo a Política Nacional de Participação Social (PNPS) e o Sistema Nacional de Participação Social (SNPS), visando, principalmente, garantir instâncias democráticas de participação na definição das políticas e na administração pública federal. O objetivo da PNPS é "fortalecer e articular os mecanismos e as instâncias democráticas de diálogo e a atuação conjunta entre a administração pública federal e a sociedade civil" (Brasil, 2014).

À primeira vista, o Decreto n. 8.243 parece direcionado a ser um instrumento formal e prático de implementação de processos que 
contribuam para a estruturação de uma sociedade em que a deliberação democrática se torne reconhecida. Tal decreto tem sido visto também como um elemento de definição de cidadania, por propiciar, supostamente, maior participação dos cidadãos nas ações da administração pública federal. Essa forma de interpretação, porém, tem se tornado objeto de uma intensa polêmica cujos contornos políticos são tanto pragmáticos como ideológicos - que levou à recusa do Decreto na votação realizada na Câmara dos Deputados em outubro de 2014.

Frente ao intenso debate que se instalou em torno da legitimidade e da pertinência do referido decreto presidencial, surge o questionamento: "A política de participação social, definida no Decreto n. 8.243, da Presidência da República do Brasil, constitui de fato uma política de democracia deliberativa?".

Ao refletir sobre essa questão, considera-se fundamental conhecer e compreender o alcance de políticas públicas que visam à estruturação de uma sociedade democrática. Devem-se avaliar também as perspectivas que ações governamentais apresentam para o fomento da participação social. Igualmente, é preciso que se tenha em conta também o papel que o despertar do engajamento social - que o senso comum e mesmo algumas análises críticas supõem estar ocorrendo na história recente do País - desempenha na definição do presente e do futuro da sociedade.

Uma consistente avaliação do Decreto com sua concepção de Estado, de política e de participação social - não pode prescindir da avaliação da atual conjuntura social e política. Tem sido praticamente um consenso entre os analistas a constatação de que o Congresso Nacional, que saiu das urnas eleitorais em 2014, tem um perfil conservador. No contexto das discussões deste artigo, entende-se por conservador aquele parlamentar ao qual interessa manter inalterados os mecanismos da democracia representativa. São conservadoras por se mostrarem pouco permeáveis a medidas que demandariam deles uma transigência maior e uma abertura a formas participativas de deliberação. Parlamentares que exercem seu poder de representação dessa forma tendem a ser refratários a qualquer medida que implica alteração no status quo das relações de poder no espaço legislativo e em suas relações com a sociedade.

Sem ignorar este fator conjuntural, o objetivo geral perseguido neste trabalho é analisar o Decreto n. 8.243 da Presidência da República do Brasil à luz da teoria da democracia deliberativa.

Busca-se identificar a natureza do decreto e suas possíveis contribuições ao confrontá-lo com uma perspectiva teórica e prática de consolidação da participação social nas políticas e nas decisões gerenciais da administração pública brasileira.

Este estudo se inicia por esta introdução, que apresenta a proposta de estudo e os resultados pretendidos. A segunda seção traz a conceituação de democracia deliberativa, seus principais elementos teóricos e as dificuldades de sua implementação. A terceira parte trata dos elementos principais do Decreto n. 8.243. Faz-se em seguida uma contraposição entre a teoria da democracia deliberativa e o decreto em questão. Por fim, nas considerações finais, apresenta-se uma 
análise sobre as possíveis contribuições desse decreto para a institucionalização de uma sociedade mais democrática e deliberativa no Brasil.

\section{Democracia deliberativa}

A reflexão que se pretende fazer aqui exige que se compreenda o que é a democracia deliberativa. Com esse intuito, apresentam-se, nesta seção, os elementos teóricos principais e alguns questionamentos e percepções sobre as possibilidades e os limites da democracia deliberativa.

Avritzer (2009) reconhece que há uma diversidade de abordagens quando se fala em democracia deliberativa, podendo ser divididas em duas fases. A primeira compreendeu os anos de 1990 e teve como foco principal a discussão sobre o conceito de "deliberação". A segunda, dos anos subsequentes, concentrou-se na factibilidade empírica da democracia deliberativa.

Marques (2009b) considera que a temática da deliberação pública é fundamental para quem quer compreender as contribuições de uma esfera de discussão pública ampliada na "construção de um sistema democrático marcado pela aproximação entre instâncias formais do governo e espaços informais de discussão entre os cidadãos" (Marques, 2009b, p. 11). Destaca ainda que diversos trabalhos acadêmicos (Coelho \& Nobre, 2004; Costa, 2002; Avritzer \& Navarro, 2003; Dagnino, 2002) investigaram empiricamente processos deliberativos e mostraram que "a deliberação não se resume a um processo pontual e elitista de elaboração de decisões" (Marques, 2009b, p. 11).
Com a ampliação dos processos comunicacionais, podem-se observar a demanda e a reivindicação, cada vez maior, por participação social nas decisões dos governos e pela garantia de direitos. Essa participação e esse reconhecimento podem ter maior efetividade e resultados por meio de processos de deliberação democrática, que exigem elementos básicos para que aconteçam de forma efetiva, com reconhecimento de minorias e grupos menos privilegiados.

Na perspectiva de Dryzek (2000), houve uma virada teórica e prática, no interior da teoria democrática, caracterizada pela incorporação, pelos principais pensadores da democracia, do conceito de deliberação. Avritzer (2009) afirma que se observa um consenso parcial, na perspectiva teórica, sobre democracia deliberativa como ela é compreendida por James Fishkin, Joshua Cohen e James Bohman, e que o elemento prático da virada deliberativa pode ser observado em instituições políticas de democracias contemporâneas (Avritzer, 2002; Fung \& Wright, 2003; Santos, 2002; Fishkin, 1995).

Segundo Marques (2009b), as democracias modernas contribuíram para a expansão do exercício da deliberação para diversos tipos de comunidade que consideram todas as pessoas como politicamente iguais, não importando a cultura, o credo, o status ou outros elementos que poderiam ser diferenciadores. Bohman (2009) destaca que as democracias constitucionais modernas geraram espaços para diferentes tipos de deliberação pública, uma vez que direitos como liberdade de fala, expressão, associação e investigação, por elas assegurados, criam condições para a deliberação bem-sucedida. Considera também que, para que possa acontecer na cole- 
tividade, a deliberação deve ser baseada no diálogo entre as pessoas. Ao mesmo tempo chama a atenção para a importância de se definir o que torna uma deliberação pública, seu alcance e as condições para ser bem-sucedida (Bohman, 1996, 2009).

Quanto à definição do termo:

a deliberação pode ser compreendida como uma atividade discursiva capaz de conectar esferas comunicativas formais e informais, nas quais diferentes atores e discursos estabelecem um diálogo, que tem por principal objetivo a avaliação e a compreensão de um problema coletivo ou de uma questão geral (Marques, 2009b, p. 13).

Embora diferentes definições de deliberação pública possam ser apresentadas, destaca-se seu "processo dialógico de troca de razões com o propósito de solucionar situações problemáticas" (Bohman, 2009, p. 36). Tal processo dialógico deve considerar a cooperação e a participação dos indivíduos que têm vínculos com a questão em pauta. Marques (2009b) destaca a importância das reflexões de Jürgen Habermas para a definição de deliberação pública. Habermas busca definir princípios de interação que assegurem a legitimidade de normas e garantam alternativas capazes de regular os conflitos oriundos do pluralismo social, representado por membros que apresentam diferentes necessidades, demandas e identidades. Marques (2009b, p. 12) chama a atenção para o fato de que "a teoria deliberativa habermasiana encontrou grande aceitação entre os principais teóricos deliberativos" e credita essa aceitação ao fato de ela considerar que a deliberação deveria oferecer uma comu- nicação legitimadora das políticas públicas, articulando "discurso institucional e a conversação cívica entre os cidadãos".

A criação das normas e políticas públicas por meio do procedimento proposto por Jürgen Habermas não realiza qualquer restrição ao conteúdo normativo. Nesse sentido, pode-se dizer que sua teoria é formal e, portanto, universal. Isso não significa, então, que a moral seja descartada, pois ela será introduzida pelos dutos do próprio procedimento. A justiça substancial, em última análise, é a imposição da visão de mundo de um grupo em relação à coletividade, por isso o procedimento descarta a predefinição dos conteúdos e investe em pressupostos de validade do discurso, permitindo que todos os atingidos pelo resultado das deliberações normativas também sejam responsáveis por sua elaboração.

Marques (2009b) destaca as contribuições que essa compreensão sobre o processo político pode oferecer para que a democracia aconteça, uma vez que indica possibilidades de procedimentos que permitam argumentações cooperativas e/ou conflitivas entre os cidadãos. Acentua ainda a importância da capacidade de diálogo entre os cidadãos, incorporando de forma positiva as suas diferenças com vistas a clarear um problema e/ou sua solução. A deliberação deve permitir aos indivíduos a possibilidade de apresentar ao próximo os seus pontos de vista, suas percepções e interpretações, obtendo deles, em um processo de diálogo respeitoso, a validação das questões apresentadas.

A questão das premissas da formação de uma teoria procedimental que conferem le- 
gitimidade à atuação estatal e ao sistema jurídico parte de uma ideia de reconstrução ${ }^{1}$ de um modelo de democracia normativa. Essa teoria confia no fato de que a "força legitimadora estaria ancorada nas próprias premissas e condições formais de justificação" (Diniz, 2006, p.163), apresentando-se como a única aposta possível após a derrocada de visões de mundo regidas por cosmovisões metafísicas (Ferreira, 2015, p.103).

Refletindo sobre o tema, Figueiredo afirma que:

as inquietações que atingiram Habermas residem no fato de ele ter percebido como várias indagações sobre os vínculos sociais estão no direito. Sob a influência da teoria do discurso, assim é que uma filosofia do direito procedimental passa a ser estrutura de fundamentação e legitimação do direito. Ela será também reconstrutiva do direito existente no sentido de que este venha a superar os estágios de validade assentado no jusnaturalismo e no positivismo (Figueiredo, 2014, p. 278).

A modernidade caracteriza-se, em relação à legitimidade, de modo a transferir o poder legítimo para um nível reflexivo de justificação. Impõe-se, assim, uma carga de racionalidade para um mundo marcado por sua falta. Por isso, Habermas considera que:

o interesse é comum, porque o consenso livre de constrangimento permite apenas o que todos podem querer; é livre de decepção, porque até a interpretação das necessidades, na qual cada indivíduo precisa estar apto para reconhecer o que ele quer, torna-se o objeto de formação discursiva da vontade. A vontade, formada discursivamente, pode ser chamada racional, porque as propriedades formais do discurso e da situação deliberativa garantem suficientemente que um consenso só pode surgir através de interesses generalizáveis, interpretados apropriadamente, pelo que quero dizer necessidades que podem ser participadas comunicativamente (Habermas, 2002, p.137).

A legitimidade floresce, nesse sentido, da transposição de um consenso racional formado no mundo da vida para o sistema jurídico sob o manto de uma norma. Dessa forma, um sistema que não se pode fundamentar apenas em uma imposição (facticidade) exige que o DNA de suas normas jurídicas seja oriundo de um procedimento democrático para que se possa falar em validade (legitimidade). A vontade exercida pelos participantes do procedimento não pode ser viciada. Logo, é necessário que se estabeleçam, como pressupostos de validade, condições que reduzam a influência dos imperativos sistêmicos da burocracia e da economia. Desde já, pode-se verificar que o projeto de dotar o Estado e o direito de legitimidade se insere em uma perspectiva contrafática.

Habermas é ciente de que esses influxos sistêmicos ocorrem e, em momento algum de sua produção acadêmica, adotou uma postura que negasse esses fatos. Contudo, como discípulo de uma teoria crítica marxista, não se contentou com o modo como as coisas estão dispostas, por isso prescreveu várias recomendações para que se possa vivenciar um procedimento realmente democrático. Por esse motivo, o filósofo alemão não estaria negligenciando nenhuma possibilidade que a racionalidade humana permite. Assim, 
sem o intuito de descrever a realidade, Habermas dirá que, para o bom funcionamento do procedimento, a racionalidade comunicativa não poderá ser cerceada por uma racionalidade instrumental. Isso quer dizer que, por meio da racionalidade comunicativa, podem-se estabelecer formas de contenção às investidas sistêmicas no mundo da vida para que elas não sejam capazes de deturpar a formação legítima do consenso.

Avritzer (2009, pp. 7-8) afirma que, na democracia deliberativa, podem-se observar quatro elementos principais: 1) "superação de uma concepção agregativa de democracia centrada no voto"; 2) identificação da racionalidade política com mudança e justificação de preferências; 3) pressuposição de "princípio de inclusão" na democracia deliberativa; 4) procura por instituições capazes de efetivar as "preferências dos indivíduos por formas amplas de discussão". Avritzer (2009, p. 8) destaca que, para ele, o quarto elemento apresentado é "o centro do cânone democrático deliberativo".

Considerando a construção teórica da democracia deliberativa, Avritzer (2009) afirma que os principais teóricos da temática são James Bohman, Joshua Cohen, Sheyla Benhabib e Maeve Cooke, os quais se destacam no "processo de construção da teoria por meio de um amplo debate teórico" (Avritzer, 2009, p. 8). Quanto à contribuição teórica de cada um desses autores, pode-se observá-la pelos textos organizados e traduzidos por Ângela Cristina Salgueiro Marques no livro $A$ deliberação pública e suas dimensões sociais, políticas e comunicativas. Esses textos são a base do referencial aqui trabalhado e dos elementos considerados como necessários para que a perspec- tiva deliberativa democrática possa acontecer em determinada sociedade.

Avritzer (2009) afirma que, para Bohman, a democracia deliberativa não deve ser definida como procedimental, mas como um conjunto de acordos cooperativos eminentemente pragmáticos. Bohman (2009) destaca que há diversas razões para defender a perspectiva deliberativa. Mesmos argumentos que aparentemente indicam problemas da deliberação costumam apresentar como contraposição benefícios que a justificam. Reconhece que a deliberação nem sempre levará à melhor decisão, pois decisões não públicas podem ser melhores do que decisões públicas. No entanto, a deliberação pública costuma melhorar a qualidade da justificação e da produção de decisões por submeter-se à maior amplitude de opiniões e possibilidades de alternativas: "defendo que a melhor defesa para a deliberação pública é que ela parece ser o melhor meio de aperfeiçoar a qualidade epistêmica das justificações para decisões políticas" (Bohman, 2009, p. 35). Destaca que deliberações em fóruns públicos abertos costumam aperfeiçoar a qualidade das razões.

Bohman (2009) considera importante a perspectiva procedimental da deliberação, citando as contribuições de Joshua Cohen e Robert Dahl, com suas listas sistemáticas de condições procedimentais. No entanto, considera que elas, embora importantes, não são suficientes para elucidar o motivo de as decisões falharem em ser democraticamente legitimadas, talvez porque as regras e as condições devessem surgir no meio da deliberação, entre aqueles que deliberam. Para Bohman (2009), a legitimidade democrática e o sucesso nas atividades deliberativas 
têm sua base no diálogo: "uma abordagem dialógica da deliberação captura melhor o processo de reinterpretação das normas e procedimentos à luz de novas experiências e situações problemáticas" (Bohman, 2009, p. 64). A deliberação pública é compreendida, dessa forma, como um diálogo que tem como objetivo a solução de um problema ou resolução de um conflito. Conclui sua análise afirmando que "talvez o principal desafio da democracia deliberativa seja solucionar os crescentes conflitos comuns sem abrir mão da igualdade política dos cidadãos, da não tirania dos resultados e da publicidade do diálogo" (Bohman, 2009, p. 81).

Em Cohen (2009), pode-se observar uma caracterização da democracia deliberativa de modo procedimentalista, como uma associação democrática na qual os membros partilham seus princípios definidores e também os objetivos do grupo, considerando a pluralidade que o constitui.

As perspectivas de Bohman (2009) e Cohen (2009) apontam para uma democracia deliberativa em que o debate e a cooperação operam considerando a pluralidade, característica da condição humana e da agregação dos seus indivíduos.

Benhabib (2009) destaca a importância da capacitação do sujeito para a participação dos processos democrático-deliberativos:

o engajamento na deliberação demanda que todos os participantes sejam capazes de formular questões próprias e passíveis de serem compreendidas e aceitas; de iniciar debates e interpretar suas necessidades de maneira reflexiva, expondo seus interesses sob uma perspectiva generali- zante (Benhabib, 1996, p. 70.).

Avritzer (2009) destaca a diferença principal entre a abordagem de Bohman e Cohen e a abordagem de Benhabib. Enquanto os primeiros não consideram importante a ideia de consenso procedimental, mas valorizam a cooperação e a associação democrática, Benhabib considera o consenso racional mais importante.

Marques (2009b) considera que a legitimidade do processo de deliberação exige um acordo, entre os envolvidos, sobre as regras e princípios normativos que definirão a natureza do vínculo entre os participantes e como serão feitas as trocas argumentativas. Apresenta como princípios a serem observados: a) igualdade, b) publicidade, c) reciprocidade, d) reflexividade, e) accountability (prestação de contas), f) autonomia, g) ausência de coerção, h) respeito mútuo.

Considerando a complexidade ou amplitude dos princípios a serem observados para a constituição da democracia deliberativa, há questionamentos sobre a exequibilidade, ou a possibilidade da realização empírica, da deliberação. Quanto a isso, diversos autores se dedicaram a indicar a possibilidade de realização prática da deliberação. Para Avritzer (2009), questões empíricas no que se refere à facticidade da democracia deliberativa são tratadas por autores como Amy Gutmann e Dennis Thompson, Jane Mansbridge e Simone Chambers. Apresentaremos aqui as contribuições de estudos de Gutmann e Thompson (2009) e de Genevieve Fuji Johnson (2011), que mostram resultados práticos obtidos em processos de democracia deliberativa. 
Gutmann e Thompson (2009, p. 177) distinguem os principais enfoques que teóricos tomam na perspectiva de definir "termos justos de cooperação política em uma sociedade democrática." Avritzer (2009) destaca a contribuição desses autores quanto à inserção de elementos não procedimentais ou substantivos na compreensão da democracia, destacando a introdução da reciprocidade, como capacidade mútua de acesso a determinados bens públicos, no "cânone deliberativo".

Como afirmam Gutmann e Thompson (2009, p. 181), "a reciprocidade assegura que os cidadãos devem uns aos outros justificativas para as leis e as políticas públicas que os vinculam mutuamente e que eles coletivamente elaboraram". Nesse sentido, é relevante a explicação fornecida por Habermas:

o entrelaçamento dos processos jurídicos com argumentações que se regulam a si mesmas, apoiando-se nos princípios da generalização e da adequação, explica a curiosa ambivalência da pretensão de validade do direito positivo. É preciso distinguir entre a validade do direito, garantida através de decisões competentes, e a validade social do direito aceito ou implantando de fato. No entanto, no próprio sentido complexo da validade do direito, manifesta-se uma ambivalência que o direito moderno adquire devido à sua dupla base da validade, que repousa no princípio da fundamentação e no da normatização. (...) Ao passo que a pretensão de validade do direito positivo não consegue fugir da contingência que cerca a sua gênese, nem da facticidade da ameaça de sanção. Mesmo assim, as normas jurídicas positivadas, emitidas conforme o processo, pretendem legitimidade. Pois o modo de validade do direito aponta não somente para a expectativa política de submissão à decisão e à coerção, mas também para a expectativa moral do reconhecimento racionalmente motivado de uma pretensão de validade normativa, a qual só pode ser resgatada através de argumentação. E os casos limites do direito da legítima defesa e da desobediência civil, por exemplo, revelam que tais argumentações podem romper a própria forma jurídica que as institucionaliza (Habermas, 2003, pp. 246-247).

A perspectiva da reciprocidade pode ajudar na definição de acordos políticos com base em princípios justificáveis a outros que compartilham o objetivo de chegar a um entendimento. Para os autores, as decisões democráticas exigem uma justificação mútua, "providenciar razões que constituem uma justificação pelo fato de impor leis vinculatórias a outras pessoas" (Gutmann \& Thompson, 2009, p. 181). Essa justificação mútua somente é possível tomando como referência valores substantivos. Para os autores, o princípio da reciprocidade indica que há outros princípios que também precisam ser observados para que se obtenha um conteúdo de democracia deliberativa, quais sejam: publicidade, accountability, liberdade básica, oportunidade básica, oportunidade justa.

Alguns teóricos, denominados por Gutmann e Thompson (2009) como procedimentalistas puros, focam nos procedimentos, considerando-os como as leis são feitas e as condições para que os procedimentos aconteçam de forma justa. No entanto, os autores apontam a necessidade de consideração, além dos procedimentos, de princípios 
substantivos como a liberdade individual ou igual oportunidade, entre outros, para que se obtenha um processo democrático justo. Para indicar a importância de incluir princípios procedimentais e substantivos na teoria democrática e deliberativa, Gutmann e Thompson (2009) fazem uso de um caso envolvendo deliberação sobre cuidados com a saúde no Reino Unido. Em 1999, o governo britânico criou um corpo deliberativo (National Institute for Health and Clinical Excellence - NICE), com especialistas e leigos, para definir acessos a tratamentos e diretrizes clínicas a serem utilizados pelo Serviço Nacional de Saúde (National Health Service - NHS), pois não havia fundos para todas as necessidades da saúde. Tomando o caso como exemplo, os autores apontam que os procedimentos somente não justificam a negação do NICE ao financiamento para uma nova droga antigripal (Anamivir). $O$ fato de a decisão ter sido deliberativa também não é suficiente para considerá-la justificável.

A reciprocidade permite aos cidadãos o acesso às justificativas que levaram à negação de uma política que pode afetar seu bem-estar. Os elementos que levaram à decisão do NICE foram expostos e ficou claro que a questão não era econômica, pois havia necessidade de mais pesquisas para comprovar a relevância e a eficácia do medicamento e que resultados positivos poderiam, no futuro, alterar a decisão tomada. Justificar a decisão pela observância dos procedimentos não seria suficiente nesse tipo de demanda, sendo necessária uma justificativa substantiva.

Outra questão significativa apontada pelos autores é o status provisório, moral e politicamente, dos princípios substantivos na democracia deliberativa. Considerar a provisoriedade é considerar a possibilidade de mudar uma decisão em outro momento. É aceitar uma perspectiva que, em determinado momento, será rejeitada, ou vice-versa. As razões políticas e/ou morais podem ter suas razões modificadas pela razão comunicativa. No caso citado pelos autores, pode-se notar a clareza do grupo quanto à provisoriedade da decisão: "o NICE também recomendou que julgamentos adicionais fossem conduzidos e dados posteriores fossem obtidos, para que sua decisão pudesse ser retomada na próxima temporada" (Gutmann \& Thompson, 2009, p. 195). Ao concluir as relações observadas entre os princípios da democracia deliberativa e o NICE, os autores destacam que, no debate sobre o NICE, na Casa dos Comuns - instituição parlamentar que, no Reino Unido, corresponde aproximadamente à Câmara dos Deputados no legislativo federal brasileiro -, críticos e defensores dele usaram tanto princípios procedimentais, quanto substantivos para apresentar suas posições.

Avritzer (2009, p. 9) destaca a importância das observações de Gutmann e Thompson indicando que eles aproximam "a democracia deliberativa da democracia real, ao colocarem a questão das oportunidades justas no campo das discussões democráticas e conectá-la com processos legislativos".

Quanto à factibilidade da democracia deliberativa, Johnson (2011) apresenta três casos práticos - Gestão dos Resíduos Nucleares Canadenses (NWMO), Habitação Social em Toronto (TCHC) e Nova Scotia Política Energética (NSP) -, que mostram elementos importantes para que a perspectiva teórica se efetive no dia a dia das organizações. John- 
son destaca fatores pertinentes a cada contexto político que comprometem o alcance dos objetivos da democracia deliberativa: princípios normativos, pressão pública, requisitos políticos, interesse estratégico, interesse econômico. Esses fatores tendem a dar suporte à motivação das elites de dividir o poder de tomada de decisão com aqueles diretamente afetados por suas políticas. Os princípios normativos se referem às grandes finalidades sociais e éticas que uma organização espera alcançar na prestação de seus serviços e gestão de seus bens. A pressão pública refere-se às exigências de mudança que um público afetado coloca para uma organização. Requisitos políticos são aqueles colocados à organização pelo seu regime regulatório global. Interesses estratégicos caracterizam imperativos organizacionais considerados importantes para garantir programas eficazes e a perenidade da organização. Finalmente, interesses econômicos se referem às condições necessárias para a manutenção ou melhora dos resultados financeiros da organização.

Os resultados dos três casos apresentados por Johnson (2011) são interessantes e ajudam a esclarecer que elementos menos altruístas podem encorajar a adesão à democracia deliberativa, pois a deliberação é uma forma de as organizações compreenderem e obterem maior aceitação em suas relações com o ambiente onde se inserem. Segundo Johnson (2011), os processos consultivos da TCHC, NSP e NWMO são impressionantes em termos de seus projetos de tomadas de decisão com base em princípios democráticos deliberativos. Ele observou que em cada caso há fatores contextuais que podem facilitar ou complicar as inclinações das elites e, portanto, as possi- bilidades, para a realização do empoderamento democrático deliberativo. $\mathrm{O}$ fator que mais chama atenção e diferencia os casos apresentados é o "interesse econômico". Ao contrário do caso do TCHC, os interesses econômicos do NSP e do NWMO não foram congruentes com o aumento do empoderamento de seus públicos afetados. Seus interesses econômicos poderiam ter sido comprometidos pelo aumento da autonomia democrática. O descompasso no fator "interesses econômicos" talvez justifique em parte que o empoderamento dos participantes nos processos de consulta foi reduzido nas duas últimas organizações. Johnson (2011) conclui que isso é potencialmente problemático para as perspectivas de realização dos objetivos teóricos da democracia deliberativa em processos de políticas públicas estabelecidas em contextos de hierarquias de poder estabelecidas e interesses econômicos dominantes.

\section{Elementos da política deliberativa no âm- bito do Decreto n. $\mathbf{8 . 2 4 3}$}

Em 23 de maio de 2014, a Presidência da República do Brasil, pelo Decreto n. 8.243, instituiu a Política Nacional de Participação Social (PNPS) e o Sistema Nacional de Participação Social (SNPS), com o objetivo de "fortalecer e articular os mecanismos e as instâncias democráticas de diálogo e a atuação conjunta entre a administração pública federal e a sociedade civil” (Brasil, 2014).

O Decreto destaca que os objetivos e as diretrizes da PNPS devem ser considerados na formulação, na execução, no monitoramento e na avaliação de programas e políticas públicas, como também no aprimoramento da gestão pública. 
controle social (Brasil, 2014).

O Decreto define como sociedade civil "o cidadão, os coletivos, os movimentos sociais institucionalizados ou não institucionalizados, suas redes e suas organizações" (Brasil, 2014). Além da conceituação de sociedade civil, são definidas as compreensões para conselho de políticas públicas, comissão de políticas públicas, conferência nacional, ouvidoria pública federal, mesa de diálogo, fórum interconselhos, audiência pública, consulta pública e ambiente virtual de participação social. $O$ decreto destaca que ele não implica na descontinuação ou alteração de nenhuma das instâncias apresentadas: "as definições previstas neste Decreto não implicam na descontinuação ou alteração de conselhos, comissões e demais instâncias de participação social já instituídas no âmbito do governo federal" (Brasil, 2014).

Quanto às diretrizes gerais da PNPS, são apresentadas no art 3o:

I - reconhecimento da participação social como direito do cidadão e expressão de sua autonomia;

II - complementariedade, transversalidade e integração entre mecanismos e instâncias da democracia representativa, participativa e direta; III - solidariedade, cooperação e respeito à diversidade de etnia, raça; IV - direito à informação, à transparência e ao controle social nas ações públicas, com uso de linguagem simples e objetiva;

V - valorização da educação para a cidadania ativa;

$\mathrm{VI}$ - autonomia, livre funcionamento e independência das organizações da sociedade civil;

VII - ampliação dos mecanismos de
Entre os objetivos da PNPS, podem-se observar, no art. 40:

I - consolidar a participação social como método de governo;

II - promover a articulação das instâncias e dos mecanismos de participação social;

III - aprimorar a relação do governo federal com a sociedade civil;

IV - promover e consolidar a adoção de mecanismos de participação social nas políticas e programas de governo federal;

$\mathrm{V}$ - desenvolver mecanismos de participação social nas etapas do ciclo de planejamento e orçamento;

VIII - incentivar e promover ações e programas de apoio institucional, formação e qualificação em participação social para agentes públicos e sociedade civil;

IX - incentivar a participação social nos entes federados (Brasil, 2014).

O Decreto determina ainda que os órgãos e entidades da administração pública federal direta e indireta considerem, ao formular e gerir programas e políticas públicas, as diversas instâncias de participação social e que apresentem relatórios anuais da implementação da PNPS, cabendo à Secretaria Geral da Presidência da República publicar anualmente avaliação da implementação da PNPS.

O Art. $7^{\circ}$ define que o SNPS será coordenado pela Secretaria Geral da Presidência da República e integrado por: 1) conselho de políticas públicas, 2) comissão de políticas públicas, 3) conferência nacional e 4) ouvi- 
doria federal, "sem prejuízo da integração de outras formas de diálogo entre a administração pública federal e a sociedade civil" (Brasil, 2014). Além disso, o Decreto define outras atribuições da Secretaria Geral da Presidência da República quanto à orientação, à implementação, ao suporte, à avaliação e ao fortalecimento da PNPS e do SNPS, bem como ao suporte que ela terá para realizar todas essas atribuições.

Entre as diretrizes mínimas a serem observadas "na constituição de novos conselhos de política e na reorganização dos já constituídos", podem-se destacar a "garantia da diversidade entre os representantes da sociedade civil" e a "publicidade" dos atos, as quais compõem as diretrizes das comissões de políticas públicas e das conferências nacionais (Brasil, 2014). É importante observar que "a participação dos membros no conselho é considerada prestação de serviço público relevante" e, por essa razão, ela não é remunerada.

As ouvidorias devem observar as diretrizes da Ouvidoria-Geral da União e da Controladoria Geral da União, que já foram definidas no Decreto n. 8.109, de setembro de 2013, e não são redefinidas neste momento.

Segundo o Decreto, as mesas de diálogo visam ao "aperfeiçoamento das condições e relações de trabalho", por isso deveriam preferencialmente envolver representantes dos empregados, dos empregadores e do governo e ter prazo de funcionamento definido. O documento em questão também define diretrizes mínimas de funcionamento dos fóruns interconselhos, das audiências públicas, das consultas públicas e dos ambientes virtuais de participação social.
Institui-se, ainda, a Mesa de Monitoramento das Demandas Sociais, "instância colegiada interministerial responsável pela coordenação e encaminhamento de pautas dos movimentos sociais e pelo monitoramento de suas respostas" (Brasil, 2014).

Deve-se destacar que as instâncias de participação social de que trata o Decreto já fazem parte da vida política do País e algumas são utilizadas pela quase totalidade dos municípios brasileiros. Em suma, o Decreto organiza e estabelece diretrizes de funcionamento de instâncias já existentes de participação social no Governo Federal. Estimula a observação dos objetivos e das diretrizes da PNPS na formulação, na execução, no monitoramento e na avaliação de programas e políticas públicas. Aumentando as possibilidades de participação da sociedade com plataformas virtuais na internet, é possível que a manifestação dos cidadãos sobre políticas públicas se torne mais efetiva.

Embora muitas vozes, representando principalmente instâncias políticas, tenham expressado certa surpresa com o Decreto, deve-se observar que ele institucionaliza práticas políticas que foram assumidas pelo governo Lula com a Medida Provisória 103. Se considerado tal fato, pode-se afirmar que ele não constitui uma novidade nas estruturas existentes no Poder Executivo. Já, nessa Medida Provisória, previam-se a articulação com as entidades da sociedade civil e a criação e implementação de instrumentos de consulta e participação popular que pudessem influenciar na elaboração da agenda da Presidência da República. Além disso, pela Constituição de 1988, artigo 84, é competência privativa do Presidente da República 
dispor sobre a "organização e funcionamento da administração federal" (Brasil, 2005), o que deve ser feito mediante decreto. Dessa forma, embora pudesse haver alguma surpresa quanto ao Decreto, não se pode dizer que ele seja incoerente com as ações anteriores do atual governo e do anterior, nem que seja um ato indevido ou autoritário por ser feito por decreto, pois é esse o procedimento definido pela Constituição Brasileira de 1988.

Manifestações contrárias e a favor do Decreto podem ser observadas na mídia e são coerentes com uma perspectiva deliberativa, uma vez que "diferentes atores e discursos estabelecem um diálogo, que tem por principal objetivo a avaliação e a compreensão de um problema coletivo ou de uma questão geral" (Marques, 2009, p. 13). Nessa perspectiva, observa-se o manifesto da UNE favorável ao Decreto:

A União Nacional dos Estudantes acredita que mais participação popular não é sinônimo de ditadura, como alguns tentam rotular, mas sim de efetiva democracia e vai ao encontro do desejo dos brasileiros/as em participar mais da vida política e decisões do país (UNE, 2014).

Enquanto algumas manifestações, principalmente por parte de membros da classe política, buscam associar o Decreto a uma perspectiva ditatorial, outras querem mostrar que ele tem sua base em uma proposta de consolidação democrática.

O interessante é observar que algumas reações posteriores à publicação do Decreto $n$. 8.243 encontram fundamento no caso NICE descrito por Gutmann e Thompson (2009) neste estudo. Nesse caso, a instância de onde partiu a maioria das críticas também foi o Legislativo. No entanto, observamos uma diferença significativa. No caso do Brasil, antes de um debate amplo sobre a pertinência ou não da institucionalização das instâncias de participação, há membros do legislativo que pretendem votar, "em regime de urgência, um decreto legislativo que anule os efeitos do decreto presidencial" (Partidos, 2014). Referindo-se ao Decreto n. 8.243, o Senador Álvaro Dias, em vídeo disponível no Youtube, afirma: "ao assinar este decreto, a presidente da República decreta a falência do poder legislativo federal e o sucateamento total e absoluto do Congresso Nacional" (Dias, 2014).

Embora também taxado como "afronta ao Legislativo" (Dias, 2014), na realidade, o Decreto trata da participação direta, que está prevista no art. 1o, parágrafo único, da Constituição Federal de 1988, onde se lê que "todo o poder emana do povo, que o exerce por meio de representantes eleitos ou diretamente nos termos desta Constituição" (Brasil, 2005). Ou seja, devem-se distinguir os processos pelos quais o cidadão pode exercer seu poder. Segundo a Constituição de 1988, o cidadão pode exercê-lo através da delegação a políticos eleitos determinadas deliberações ou atuando diretamente em defesa dos seus interesses, incluindo aí diversas formas de organização. Quanto ao processo de delegação, o Decreto não altera nada, não fazendo nenhuma menção que implique mudanças.

Avritzer (2009, p. 7) afirma que, na democracia deliberativa, podem-se observar quatro elementos principais, sendo o primeiro a "superação de uma concepção agregativa de democracia centrada no voto." Perspectivas além da democracia representativa, a princí- 
pio, ajudam a consolidar a democracia em suas diversas possibilidades. O Decreto é Constitucional e apresenta como possibilidade a superação da concepção de democracia centrada no voto.

Considerando-se tanto a deliberação democrática quanto o Decreto n. 8.243, não se observam contradições. Tampouco parece haver incompatibilidades entre ambos. Pelo contrário, o Decreto está em consonância com a deliberação, uma vez que busca institucionalizar espaços para o exercício da cidadania e da construção social. As instâncias reconhecidas e institucionalizadas pelo Decreto permitem e garantem a perpetuação da deliberação, pois ela "se configura como um processo que se realiza, grande parte das vezes, como um processo continuado ao longo do tempo, resultando de debates, de conversações cívicas e de discussões políticas [...] produzidas em múltiplos contextos [...], sejam eles formais, informais ou mediáticos" (Marques, 2009b, p. 22).

Nassif (2014) apresenta dados sobre a presença das instâncias objeto do Decreto na nossa sociedade: "São 40 Conselhos e Comissões de Políticas Públicas, formados por 668 representantes do governo e 818 representantes da sociedade civil"; "Já foram realizadas 128 Conferências Nacionais desde a promulgação da CF/88, sendo 97 delas entre 2003-2013"; "Existem 286 ouvidorias públicas federais"; "Cerca de $85 \%$ dos programas do Governo Federal possuem interfaces socioestatais (ouvidorias, mesas de diálogo, audiências públicas, consultas públicas, conselhos, conferências, plataformas virtuais)"; Além disso, destaca a participação social no planejamento estratégico da administração pública federal. "No último
PPA (Plano Plurianual), foram apresentadas 629 contribuições da sociedade civil, das quais $77 \%$ foram incorporadas integralmente".

Por esse motivo, institucionalizar essas formas de participação e deliberação pelo Decreto pode ser considerada um modo de procedimentalizar a perspectiva deliberativa, da mesma forma como foi feita nos casos apresentados por Gutmann e Thompson (2009) e Johnson (2011). Tanto no Decreto, quanto nos casos apresentados por esses autores, observamos a estruturação ou institucionalização de espaços deliberativos com vistas a gerar participação das pessoas implicadas pelos desdobramentos de processos decisórios.

A variedade de instâncias deliberativas e sua distribuição por diferentes entes federativos que a elas podem livremente aderir permite observar a perspectiva de que a deliberação não pode ficar restrita a alguns grupos, mas precisa estar aberta à ampla participação das pessoas nas decisões políticas. Quando consideramos princípios substantivos como a liberdade individual ou oportunidades iguais (Gutmann \& Thompson, 2009), torna-se fundamental que as instâncias de participação sejam ampliadas. Os espaços de participação democrática efetivamente disponíveis ao cidadão, na democracia focada na representação, são praticamente nulos. Não há oportunidades iguais para que o indivíduo expresse suas demandas, nem espaço público disponível para isso.

Como o Decreto define diretrizes mínimas a serem observadas para a constituição de novos conselhos de política ou para a reorganização dos já constituídos, indica que, 
sob demanda social, novos espaços podem ser criados para, eventualmente permitir que cidadãos com novas demandas participem da deliberação. Embora se referindo às decisões tomadas por instâncias deliberativas, Gutmann e Thompson (2009) apresentam o princípio da provisoriedade, ou seja, consideram a possibilidade de se mudar uma decisão em outro momento. No entanto, talvez seja possível avançar ainda mais nessa questão indo além da provisoriedade das decisões tomadas. Sendo o mundo social provisório e passível de se reorganizar a cada momento, pode-se falar da provisoriedade das instâncias deliberativas. Isso pode levar à demanda por novas instâncias e o fechamento de outras para atender às demandas efetivas da cidadania.

Gutmann e Thompson (2009) apresentaram o caso britânico do NICE, que orientava o governo na definição de políticas e alocação de recursos na área de saúde e decisões sobre investimentos ou não em determinadas alternativas. Pode-se observar que o Decreto aqui discutido também busca garantir que diferentes instâncias de participação institucionalizadas sejam consideradas para a definição da Agenda Presidencial e para a "formulação, execução, monitoramento e avaliação de programas e políticas públicas" (Brasil, 2014). Além disso, essas instâncias devem ser consideradas para 0 aprimoramento da gestão pública, aproximando governo e cidadãos.

Ao definir que o SNPS será coordenado pela Secretaria Geral da Presidência da República e integrado por conselhos de políticas públicas, comissão de políticas públicas, conferência nacional e ouvidoria federal, o Decreto busca garantir a perenidade da pro- posta de participação social, desvinculando-a de partidos políticos e vinculando-a ao poder executivo eleito pela democracia representativa. Dessa forma, busca-se também a garantia de que a participação democrática possa acontecer de forma indireta pelos representantes eleitos e diretamente pela participação em diversas instâncias deliberativas. Contrariamente ao alegado por alguns críticos, as instâncias políticas características da democracia representativa, expressas nos poderes Legislativo e Executivo, permanecem intactas e com as mesmas atribuições que sempre tiveram. Acrescenta-se somente que as instâncias legislativas e executivas podem contar com instâncias de participação social para melhorar a compreensão das demandas sociais e a vinculação efetiva das decisões às diferentes realidades sociais. Além disso, o cidadão poderá, pela participação direta, em diversas instâncias, expressar seus argumentos e justificar suas demandas, submetendo-as a outros sujeitos em condições de igualdade e de forma dialógica com vistas a alcançar uma decisão sobre determinada situação ou problema que o implica, de forma a estruturar uma deliberação intersubjetivamente.

O Decreto da PNPS pretende uma aproximação da política às diferentes instâncias de participação, o que pode ser visto como uma possibilidade de "providenciar razões que constituem uma justificação pelo fato de impor leis vinculatórias a outras pessoas" (Gutmann \& Thompson, 2009, p. 181). A participação da sociedade civil na discussão de seus problemas parece permitir compreendê-los melhor e justificar eventuais decisões e legislações não populistas, porém necessárias. 
A criação de diferentes espaços, ou instâncias de deliberação, também pode ser compreendida como contemporânea. Bohman (2009) destaca que as democracias constitucionais modernas geraram espaços para diferentes tipos de deliberação pública, uma vez que direitos como liberdade de fala, expressão, associação e investigação, por elas assegurados, criam condições para a deliberação bem-sucedida. O que parece necessário é que todos efetivamente tenham garantidos os direitos de liberdade de fala, expressão e associação.

Em seu manifesto, a UNE considera o Decreto importante para a consolidação da democracia: "criar uma Política Nacional de Participação Popular, na qual o Estado brasileiro se abre para o povo, é um passo importante na consolidação de nossa democracia" (UNE, 2014). Acrescenta ainda que estranha não haver manifestação contrária, por parte de quem o critica, em relação ao financiamento privado de campanha, que cria risco à representatividade no nosso sistema político. A abertura para instâncias de discussão com o povo é consonante com as práticas democráticas, que envolvem um "processo dialógico de troca de razões com o propósito de solucionar situações problemáticas" (Bohman, 2009, p. 36). Avritzer (2014) indica que modelos de maior participação social estão presentes nas principais democracias do mundo. Cita como exemplos: "Os Estados Unidos têm o modelo de participação da sociedade civil no meio ambiente por meio dos chamados "Habitat Conservation Plannings". A França tem o modelo de participação da sociedade civil nas políticas urbanas através de contratos de gestão nos chamados "Quartier Difficile". A Espanha tem a participação da sociedade civil no meio ambiente por meio de "juris cidadãos". A Inglaterra instituiu minipúblicos com participação da sociedade civil para determinar "prioridades políticas na área de saúde". Dessa forma, pode-se afirmar que o Decreto está em consonância com movimentos mais recentes de diversas sociedades democráticas, que buscam na participação da sociedade civil uma democracia que consiga atender melhor às demandas de seus cidadãos.

O Decreto define como diretrizes mínimas a serem observadas na constituição de novos conselhos de política e na reorganização dos já constituídos a "garantia da diversidade entre os representantes da sociedade civil e a publicidade de seus atos", que são, entre outros elementos, necessários para a deliberação pública. Como afirma Bohman (2009, p. 65): "a deliberação pública tem que tomar muitas formas. Ainda assim, essas atividades são democráticas na medida em que são consistentes com os princípios de igualdade, não tirania e publicidade". A perspectiva da igualdade somente é possível em decorrência de as pessoas terem espaço nos quais possam se inserir e ter seus direitos reconhecidos pelas possibilidades de diálogos que reconheçam suas razões. A garantia da diversidade nas instâncias de participação parece favorecer o reconhecimento de cidadãos que muitas vezes não são representados em suas demandas.

Entre as diretrizes gerais da PNPS, destaca-se o "reconhecimento da participação social como direito do cidadão e expressão de sua autonomia" e a "valorização da educação para a cidadania ativa". Embora a participação social seja fundamental, as decisões podem não atender às demandas sociais 
"se os participantes não forem capazes de coordenar todas as várias perspectivas em direção a uma perspectiva comum, através de um processo dialético de constante enriquecimento e novas articulações" (Bohman, 2009, p. 77). Dessa forma, "valorização da educação para a cidadania ativa" é elemento fundamental para a consolidação democrática e a ação social. Sua presença no Decreto indica a perspectiva de garantir que princípios fundamentais da democracia deliberativa possam se efetivar.

Entre os objetivos da PNPS, estão a consolidação da participação social como método de governo e a promoção da articulação das instâncias e dos mecanismos de participação social. Esta última, segundo Avritzer (2014), traz para a política um sistema de representação de interesses que os partidos não são mais capazes de exercer. "O que ele [o Decreto] faz é aprofundar a democracia da mesma maneira que as principais democracias do mundo o fazem, ao conectar mais fortemente sociedade civil e Estado" (Avritzer, 2014).

O Decreto determina ainda que os órgãos e entidades da administração pública federal direta e indireta considerem, ao formular e gerir programas e políticas públicas, as diversas instâncias de participação social. Essa perspectiva vai de encontro com outro elemento que Avritzer (2009 p. 8) afirma ser fundamental na democracia deliberativa: a procura por instituições capazes de efetivar as "preferências dos indivíduos por formas amplas de discussão". O Decreto não só institucionaliza as diferentes instâncias de participação como determina que elas sejam consideradas nas decisões da gestão pública com vistas a atender melhor as preferências dos indivíduos. Isso depende de discussão com a participação destes últimos, o que não acontece quando os espaços políticos ficam restritos aos grupos eleitos e/ou pessoas que têm relação direta com eles. O Decreto aumenta a chance de efetivação das demandas da sociedade com a implantação da Mesa de Monitoramento das Demandas Sociais, "instância colegiada interministerial responsável pela coordenação e encaminhamento de pautas dos movimentos sociais e pelo monitoramento de suas respostas" (Brasil, 2014).

Finalmente, a criação de ambientes virtuais de participação social (Decreto, n. 8.243) responde à demanda de ampliação dos processos comunicacionais e participação social nas decisões dos governos (Marques, 2009b).

As análises aqui feitas consideram basicamente elementos relacionados com os princípios procedimentais que envolvem a constituição de espaços adequados à deliberação, pois o Decreto é direcionado à institucionalização da participação social na democracia brasileira. No entanto, para que a democracia deliberativa aconteça efetivamente, além da garantia dos princípios procedimentais, é necessário observar princípios substantivos, os quais precisam que os primeiros ofereçam a base para sua realização.

Uma nação que busca concretizar uma ideia de Estado Democrático de Direito não pode admitir que inserções legislativas que aumentem a participação popular e introduzem uma carga maior de legitimidade nas deliberações políticas sejam descartadas. $\mathrm{O}$ consenso a ser perseguido é o formado por interações plurais, em que a opinião do des- 
tinatário da formação consensual não pode ser descartado. Desse modo, pode-se esperar que a sociedade civil alcance posição de destaque, dada sua qualidade intrínseca como atriz principal em uma democracia deliberativa plural.

\section{Considerações finais}

As reações das pessoas, em grande parte, demonstram limitações na compreensão do Decreto e das possibilidades de participação oferecidas pela democracia. Em alguns casos, apresentam argumentos que não esclarecem a opinião pública e criam analogias com outros países criando posicionamentos com base no medo e não no esclarecimento. Parece faltar um elemento fundamental para a legitimidade democrática e o sucesso nas atividades deliberativas: o diálogo (Bohman, 2009).

É interessante observar que as manifestações de junho de 2013 foram vistas por muitos estudiosos como direcionadas contra a falta de escuta e o distanciamento das instâncias políticas em relação às efetivas demandas dos cidadãos, expressas por diferentes grupos sociais. Para Avritzer (2014), o Decreto, ao introduzir uma participação menos partidária e com menor defesa de interesses privados na política, busca reconstituir mais fortemente esse laço.

Johnson (2011) observou que a realização dos objetivos teóricos da democracia deliberativa é complexa em contextos de hierarquias de poder estabelecidas e interesses econômicos dominantes. Essa conclusão é significativa para o contexto brasileiro atual, pois, ao que parece, há instâncias e sujeitos preocupados com possíveis mudanças nas estruturas de poder e reflexos disso nos interesses econômicos dominantes no País. Deve-se considerar que o Decreto não fará milagre no sentido de habilitar, ou melhor, qualificar os cidadãos para uma efetiva deliberação e exercício dos direitos públicos e civis.

A criação de instâncias e espaços de deliberação exige, além da definição de procedimentos democrático-deliberativos, a capacitação dos sujeitos, dos cidadãos, para a deliberação:

A política deliberativa é elaborada em uma rede complexa de discussões e discursos na qual os cidadãos aprendem a construir argumentos, a se expressarem e a assumirem uma posição, justificando-a sempre que for necessário para chegar a uma compreensão mútua acerca de um problema público (Marques, 2009b, p. 20).

Por esse motivo, pode-se considerar o Decreto um passo importante na construção dos espaços e condições adequadas para o exercício da cidadania e na criação de uma sociedade mais democrática e ciente de suas possibilidades e limitações.

O Decreto assinala a importância da "valorização da educação para a cidadania ativa" (Brasil, 2014), o que parece um dos grandes gargalos para a constituição efetiva de uma democracia deliberativa. Ainda seria preciso avançar na educação geral e política para que se tenham ambientes efetivamente deliberativos. Ao mesmo tempo, a prática da participação em instâncias deliberativas é oportunidade para que essa educação aconteça. Isso se faz necessário para que se avance em busca não só de espaços de democracia 
deliberativa, mas sobretudo da consolidação da democracia no país. Bohman (2009) destaca que deliberações em fóruns públicos abertos costumam aperfeiçoar a qualidade das razões.

Quando se consideram os objetivos, as diretrizes e as instâncias instituídas pelo Decreto n. 8.243, pode-se afirmar que ele atende aos princípios da deliberação democrática e tem elementos que poderiam contribuir para a consolidação da democracia no Brasil. Aos que acreditam que a deliberação direta é "perigosa" para a democracia, poder-se-iam recuperar dois questionamentos de Gutmann e Thompson (2009, p. 191): "Será que os corpos responsáveis pelo processo de tomada de decisão reúnem representantes de todas as pessoas que são mais afetadas pela decisão a ser tomada? Será que os representantes são accountable diante de todos os que os elegeram?". No contexto em que a sociedade acusa o distanciamento das instâncias políticas das demandas efetivas da sociedade, o Decreto n. 8.243 surge como instrumento que busca a aproximação dos representantes eleitos com os cidadãos em suas diferentes instâncias de deliberação.

Esse ponto de vista é corroborado por Avritzer (2014), quando afirma que:

todas as principais democracias do mundo procuram soluções para o problema da baixa capacidade do parlamento de aprovar políticas demandadas pela cidadania. A solução principal é o envolvimento da sociedade civil na determinação de políticas públicas.

Deve-se reconhecer que mesmo processos democrático-deliberativos são vulneráveis a interesses diversos. Os resultados dos três casos apresentados por Johnson (2011) mostram que elementos menos altruístas encorajaram a adesão à democracia deliberativa. Da mesma forma, a tentativa de manter o poder nas mãos de uma pequena classe política pode levar à rejeição de propostas que buscam ampliar a democracia através do reconhecimento de instituições de participação social.

Infelizmente, no Brasil, ocorrem muitos escândalos de corrupção povoando os espaços políticos, tanto no Executivo quanto no Legislativo. Esse fato atesta a importância de ampliar as instâncias de participação social para que $o$ atendimento aos direitos $e$ interesses do povo não dependa somente da classe política, que, com freqüência, tem demonstrado não ouvir as vozes e os clamores de seus eleitores. Isso se torna ainda pior quando os políticos sucumbem a interesses econômicos e projetos pessoais de poder.

\section{REFERÊNCIAS}

Avritzer, L. (2002). Democracy and the Public Space in Latin America. Princeton: Princeton University Press.

Avritzer, L., \& Navarro, Z. (Org.). (2003). A inovação democrática no Brasil: o orçamento participativo. São Paulo: Cortez.

Avritzer, L. Prefácio. In: Marques, A. C. S. (Org. e trad.). A deliberação pública e suas dimensões sociais políticas e comunicativas: textos fundamentais. Belo Horizonte: Autêntica Editora, 2009. pp. 7-10.

Avritzer, L. (2014). Por que o novo decreto de 
Dilma não é bolivariano. Carta Capital, 10 jun. em 20 jun. 2014, de www.cartacapital. com.br/politica/por-que-o-novo-decreto-de-dilma-nao-e-bolivariano-8992.html

Benhabib, S. (2009). Rumo a um modelo deliberativo de legitimidade democrática. In: Marques, Ângela C. S. (Org. e trad.). A deliberação pública e suas dimensões sociais políticas e comunicativas: textos fundamentais. Belo Horizonte: Autêntica. pp. 109-141.

Bohman, J. (2009). O que é a deliberação pública? Uma abordagem dialógica. In: Marques, A. C. S. (Org. e trad.). A deliberação pública e suas dimensões sociais políticas e comunicativas: textos fundamentais. Belo Horizonte: Autêntica. pp. 31-84.

Bohman, J. (1996). Public deliberation; pluralism, complexity and democracy. Cambridge, Mass: MIT Press.

Brasil. (2005). Constituição da República Federativa do Brasil. 35.ed. São Paulo: Saraiva.

Brasil. Presidência da República. Decreto n. 8.243. Recuperado em 10 jun. 2014, de www.planalto.gov.br/ccivil_03/_Ato20112014/2014/Decreto/D8243.htm

Chambers, S. (2009). A teoria democrática deliberativa. In: Marques, Ângela C. S. (Org. e trad.). A deliberação pública e suas dimensões sociais políticas e comunicativas: textos fundamentais. Belo Horizonte: Autêntica.pp. 239-267.

Coelho, V. S., \& Nobre, M. (Org.). (2004). Participação e Deliberação: teoria democrática e experiências institucionais no Bra- sil contemporâneo. São Paulo: Ed. 34.

Cohen, J. (2009). Deliberação e Legitimidade Democrática. In: Marques, A. C. S. (Org. e trad.). A deliberação pública e suas dimensões sociais políticas e comunicativas: textos fundamentais. Belo Horizonte: Autêntica. pp. 85-108.

Cooke, M. (2009). Cinco Argumentos a favor da Democracia Deliberativa. In: Marques, A. C. S. (Org. e trad.). A deliberação pública e suas dimensões sociais políticas e comunicativas: textos fundamentais. Belo Horizonte: Autêntica. pp.143-174.

Costa, S. (2002). As cores de Ercilia. Belo Horizonte: Ed. UFMG.

Dagnino, E. (Org.). (2002). Sociedade Civil e espaços públicos no Brasil. São Paulo: Paz e Terra.

Dias, Álvaro. Apresentação de decreto do Legislativo para sustar os efeitos do Decreto n. 8.243. YouTube, 2 de junho de 2014. Recuperado em 19 jul. 2014, de www.youtube. $\mathrm{com} /$ watch?v=Nh1tKGaJdVk

Diniz, Antonio Carlos de Almeida. (2006). Teoria da legitimidade do direito e do Estado: uma abordagem moderna e pós-moderna. São Paulo: Landy.

Dryzek, J. (2000). Deliberative democracy and beyond: liberals, critics, contestations. Oxford: Oxford University Press.

Ferreira, R. A. M. (2015). Jurisdição constitucional agressiva: o STF e a democracia deliberativa de Jürgen Habermas. Rafael Alem Mello Ferreira./Curitiba: Juruá. 
Figueiredo, E. H. L. (2014). Crítica aos princípios do direito moderno. Porto Alegre: Sergio Antonio Fabris.

FISHKIN, J. (1995). The voice of the people: Public opinion and democracy. New York: Yale University Press.

Fung, A., \& Wright, E. O. (2003). Deepening democracy: institutional innovations in empowered participatory governance. London: Verso.

Gutmann, A, \& Thompson, D. (2009). Democracia Deliberativa para além do processo. In: Marques, Ângela C. S. (Org. e trad.). A deliberação pública e suas dimensões sociais políticas e comunicativas: textos fundamentais. Belo Horizonte: Autêntica. pp. 177-206.

Habermas, J. (2002). A crise de legitimação no capitalismo tardio. Tradução de Vamerich Chacon. 2. ed. Rio de Janeiro: Tempo Brasileiro.

Habermas, J. (2003a). Direito e democracia: entre a facticidade e validade. Tradução de Flávio Beno Siebeneichler. vol. 1, 2. ed. Rio de Janeiro: Tempo Brasileiro.

Habermas, J. Direito e democracia: entre a facticidade e validade. 2. ed. Tradução de Flávio Beno Siebeneichler. Rio de Janeiro: Tempo Brasileiro, 2003b. v. II.

Habermas, J. (1983). Problemas de legitimação no Estado Moderno para a reconstrução do materialismo histórico.São Paulo: Brasiliense.
Johnson, G. F. (2011). The Limits of Deliberative Democracy and Empowerment; Elite Motivation in Three Canadian Cases. Canadian Journal of Political Science. [s.I.], v. 44, n. 1, março. pp. 137-159.

Mansbridge, J. (2009). A conversação cotidiana no sistema deliberativo. In: Marques, A. C. S. (Org. e trad.). A deliberação pública e suas dimensões sociais políticas e comunicativas: textos fundamentais. Belo Horizonte: Autêntica. pp. 207-237.

Marques, A. C. S. (Org. e trad.). (2009a). A deliberação pública e suas dimensões sociais políticas e comunicativas: textos fundamentais. Belo Horizonte: Autêntica.

Marques, A. C. S. As interseções entre o processo comunicativo e a deliberação pública. In: Marques, A. C. S. (Org. e trad.). (2009b). A deliberação pública e suas dimensões sociais políticas e comunicativas: textos fundamentais. Belo Horizonte: Autêntica Editora. pp.11-28.

Nassif, L. Uma cartilha para entender a Política Nacional de Participação Social. Jornal GGN. Recuperado em 18 jul. 2014, de http:// jornalggn.com.br/noticia/uma-cartilha-para-entender-a-politica-nacional-de-participacao-social

Partidos tentam barrar decreto bolivariano de Dilma. Veja. 3 jun. 2014. Recuperado em 19 jul. 2014, de http://veja.abril.com.br/noticia/brasil/partidos-tentam-barrar-decreto-bolivariano-de-dilma

Santos, B. (Org.) (2002). Democratizar a democracia: os caminhos da democracia participativa. Rio de Janeiro: Civilização Brasi- 
leira.

UNE (União Nacional dos Estudantes). Quem tem medo da democracia? Nota pela efetiva implantação do Programa Nacional de Participação Social. Recuperado em 18 jul. 2014, de www.une.org.br/2014/06/ quem-tem-medo-da-democracia

\section{NOTA}

1. A ideia de reconstrução empregada por Habermas pode ser definida pelo seguinte trecho da obra Para a reconstrução do materialismo histórico: "uma teoria é desmontada e recomposta de modo novo, a fim de melhor atingir a meta que ela própria fixou: esse é o modo normal (...) de se comportar diante de uma teoria que, sob diversos aspectos, carece de revisão, mas cujo potencial de estímulo não chegou ainda a se esgotar" (Habermas, 1983, p. 11). 